\title{
In Situ Imposing Bias ATR-FTIR Observation at Hydrogen Terminated Si(111) Electrode Surface-Modified with Adsorbed Monolayer
}

\author{
Toshihito Ohtake ${ }^{1^{*}}$, Ken-ichiro Iijima ${ }^{2}$ \\ ${ }^{1}$ Department of Environmental Science, Faculty of Life and Environmental Sciences, Prefectural University of Hiroshima, \\ Hiroshima, Japan \\ ${ }^{2}$ Department of Mechanical Systems Engineering, Faculty of Engineering, Aichi University of Technology, Aichi, Japan \\ Email: *ohtake@ed.pu-hiroshima.ac.jp
}

How to cite this paper: Ohtake, T. and Iijima, K. (2019) In Situ Imposing Bias ATR-FTIR Observation at Hydrogen Terminated Si(111) Electrode Surface-Modified with Adsorbed Monolayer. Journal of Surface Engineered Materials and Advanced Technology, 9, 29-37.

https://doi.org/10.4236/jsemat.2019.93003

Received: April 2, 2019

Accepted: June 11, 2019

Published: June 14, 2019

Copyright (๑) 2019 by author(s) and Scientific Research Publishing Inc. This work is licensed under the Creative Commons Attribution International License (CC BY 4.0).

http://creativecommons.org/licenses/by/4.0/

\begin{abstract}
Since hydrogen-terminated Si surface has hydrophobicity, it is expected that adsorbed monomolecular film of surfactant will be formed on the Si surface in aqueous solution containing the surfactant. Such an adsorbed monolayer film is very effective for the development of a functional electrode. In this study, we have investigated the state of adsorption about an aerosol OT as the monolayer on the electrode surface and its orientation with hydrogen-terminated $\mathrm{Si}(111)$ surface by in situ ATR-FTIR spectroscopy. At this time, in situ observation performed while imposing bias to the electrode. The results suggested that the aerosol OT were desorbed by the oxidation of back-bonds in the Si atoms on the electrode surface under the imposing noble potential, although no change was observed especially when imposing less-noble potential.
\end{abstract}

\section{Keywords}

Semiconductor Electrode, Silicon, Hydrogen Termination, Oxidization, In-Situ ATR-FTIR

\section{Introduction}

Functional materials have been developed by modifying organic monolayer onto material surfaces such as metals or semiconductors, etc., and to apply them as various functional surfaces. In particular, single crystal $\mathrm{Si}$ is industrially important, and it is drawing attention as a substrate for functional and molecular devices. If the organic monolayer can be controlled and modified on the Si surface, 
it can be useful next generation devices. Especially in these fields, the researches on electronics and novel materials using self-assembled monolayers (SAM) are actively studied, and many interesting results are reported [1]-[6]. In this study, we have tried to control the $\mathrm{Si}(111)$ surface by the organic monolayer.

It is known that the $\mathrm{Si}$ oxide layer on the $\mathrm{Si}(111)$ surface is etched with an aqueous $\mathrm{HF}, \mathrm{NH}_{4} \mathrm{~F}$ aqueous solution, furthermore, the $\mathrm{Si}$ atom on the surface is terminated with hydrogen and becomes a flat surface at the atomic level [7] [8] [9]. Utilization of a surfactant solution to the Si substrate allows self-assembly of monolayer at the solid-liquid interface due to the interaction between the hydrophobicity of the H-terminated Si surface and the hydrophobic portion of the alkyl chain of the surfactant. This is called SAM film, which spontaneously generates a structure according to the properties unique to atoms or molecules, so that it would be possible to precisely manipulate and control atoms. Furthermore, by applying a potential from the outside, if adsorption and orientation of the SAM film can be controlled, a new function will be given [10] [11] [12] [13] [14]. In spite of that, there are not many detailed reports including their in-situ measurement.

In particular, notice on biological membranes, phospholipids, which are the main substances constituting them, constructed by amphiphilic substances having a hydrophobic group consisting of two alkyl chains and a hydrophilic group. The biomembrane is formed on the basis of a bilayer membrane of this phospholipid, and has a structure in which the hydrophobic groups face each other and the hydrophilic groups are directed to the aqueous phase on both sides of the membrane. When one of the phospholipids is considered as a hydrophobic substrate, the structures of the two are very similar, and an adsorbed monolayer consisting of a double-stranded surfactant is a model for elucidating the function of a biological bilayer. Therefore, in this study, we investigated in detail the adsorption monolayer of double-stranded surfactant using in situ ATR-FTIR.

\section{Experimental}

The $\mathrm{Si}$ wafer was used as single crystal n-type $\operatorname{Si}(111)(\mathrm{CZ},<500 \Omega \cdot \mathrm{cm})$. The 0.5 $\mathrm{mm}$ thick wafer was cut into $50 \mathrm{~mm} \times 17 \mathrm{~mm}$, both ends were mirror polished at $45^{\circ}$ and processed into a prism shape for ATR measurement. RCA cleaning was performed as pretreatment for the Si prism. First boiled for 10 minutes in a solution of conc. $\mathrm{H}_{2} \mathrm{SO}_{4}: 30 \% \mathrm{H}_{2} \mathrm{O}_{2}=4: 1$, and washed with deionized water (Milli-Q, $18 \mathrm{M} \Omega$ ). Then it was immersed in $5 \% \mathrm{HF}$ for 5 minutes and washed with deionized water. Subsequently, the sample was immersed in a solution heated to $80^{\circ} \mathrm{C}$ which was $25 \% \mathrm{NH}_{4} \mathrm{OH}: 30 \% \mathrm{H}_{2} \mathrm{O}_{2}: \mathrm{H}_{2} \mathrm{O}=1: 1: 5$, and rinsed with deionized water. It was immersed in a solution which was conc. $\mathrm{HCl}: 30 \% \mathrm{H}_{2} \mathrm{O}_{2}: \mathrm{H}_{2} \mathrm{O}=1: 1: 6$ heated to $80^{\circ} \mathrm{C}$ for 10 minutes, and rinsed with deionized water. By these operations, organic substances, fine particles and metal ions on the Si surface were removed. Finally, it was boiled for 10 minutes in a mixed solution of conc. $\mathrm{H}_{2} \mathrm{SO}_{4}: 30 \% \mathrm{H}_{2} \mathrm{O}_{2}=1: 1$ to form a chemically oxidized film on the $\mathrm{Si}$ surface, and 
washed with deionized water. Thereafter, the water adhering to the Si surface was removed with $\mathrm{N}_{2}$.

The Si prism was set in the electrochemical ATR cell of Figure 1, and an In-Ga alloy was applied to the back surface of the Si prism to establish conduction with the $\mathrm{Cu}$ wire by ohmic contact for forming a working electrode. The reference electrode was $\mathrm{Ag} / \mathrm{AgCl}$, and the counter electrode was $\mathrm{Pt}$ wire wound in a coil shape.

Next, deionized water was circulated by a bellows pump as shown in Figure 2, infrared light was incident on the Si prism at an incident angle of $45^{\circ}$ while circulating deionized water, and the spectrum was used as a reference. Further, while circulating $5 \% \mathrm{HF}$ aqueous solution for 10 minutes, the Si surface was hydrogen-terminated and washed with deionized water by circulating it. Subsequently, while circulating a $40 \% \mathrm{NH}_{4} \mathrm{~F}$ aqueous solution for $7 \mathrm{~min}$, the Si surface

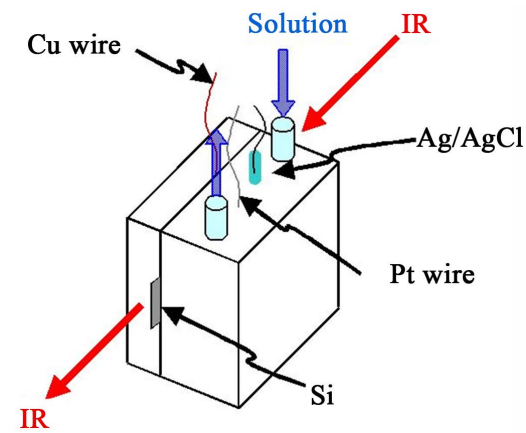

Figure 1. In situ electrochemical ATR-FTIR cell. A Si prism was set in the electrochemical ATR cell, and an In-Ga alloy was applied to the back surface of the Si prism to establish conduction with the $\mathrm{Cu}$ wire by ohmic contact for forming a working electrode. The reference electrode was $\mathrm{Ag} / \mathrm{AgCl}$, and the counter electrode was $\mathrm{Pt}$ wire wound in a coil shape.

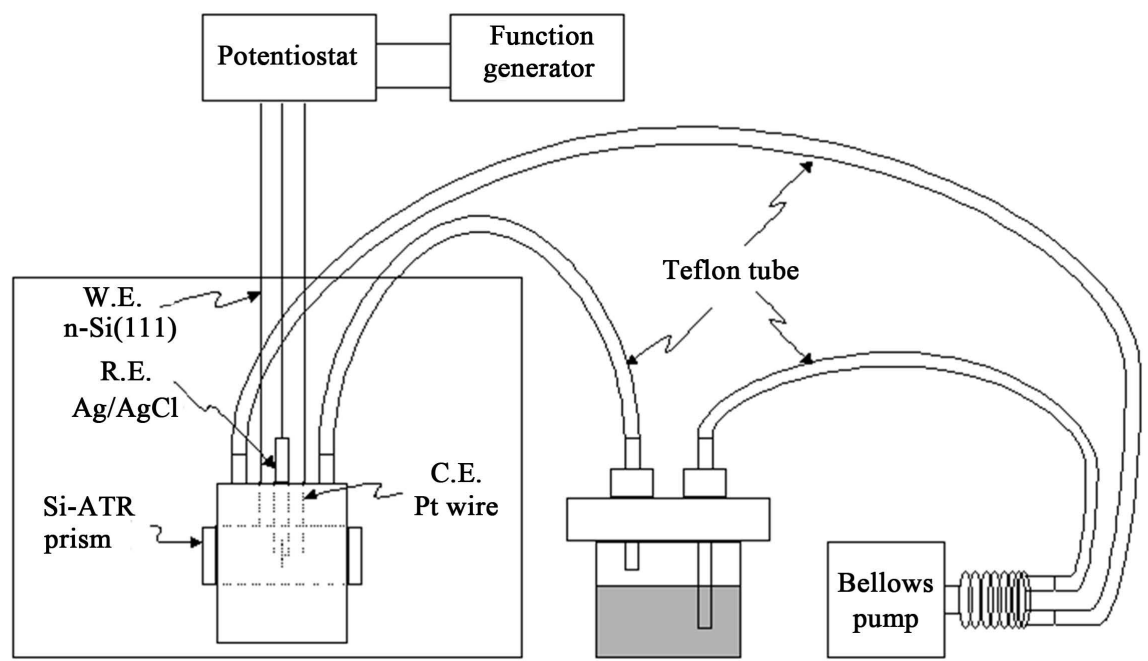

Figure 2. Flowing system to measure in situ imposing bias ATR-FTIR. The Si prism was set in the cell and put in the IR measurement device together with the cell. Deionized water was circulated in the cell by a bellows pump, infrared light was made incident on the Si prism at an incident angle of $45^{\circ}$ while circulating the deionized water, and measurement was performed, and the spectrum was used as a reference. 
was flattened at the atomic level and washed with deionized water by circulating it. At this stage, IR measurement was carried out while circulating deionized water.

Subsequently, an aqueous solution of $1 \times 10^{-2} \mathrm{M}$ di-2-ethylhexyl sulfosuccinate (Aerosol OT; Wako Pure Chemical Industries, Ltd) was passed for $240 \mathrm{~min}$, and then in situ IR measurement was conducted under no imposing bias. Furthermore, the potential was imposing to $-700 \mathrm{mV}$ (vs. $\mathrm{Ag} / \mathrm{AgCl}$ ) or $+700 \mathrm{mV}$ (vs. $\mathrm{Ag} / \mathrm{AgCl}$ ) to the surface modified $\mathrm{Si}(111)$, and the change over time was measured.

\section{Results and Discussions}

An oxide thin film on $\mathrm{Si}(111)$ was formed by cleaning the surface previously with $\mathrm{H}_{2} \mathrm{SO}_{4} / \mathrm{H}_{2} \mathrm{O}_{2}$ solution. After setting up the $\mathrm{Si}(111)$ to this circulation system as shown in Figure 2, hydrogen termination on the $\mathrm{Si}(111)$ surface was carried out by etching with circulating $\mathrm{NH}_{4} \mathrm{~F}$ solution. In order to ascertain hydrogen termination on the surface was carried out, $\mathrm{Si}(111)$ was taken out of the system and IR measurement was carried out ex situ. This result is shown in Figure 3. This peak is assigned to the $\mathrm{Si}-\mathrm{H}$ vibration peak at the terrace formed on the $\mathrm{Si}(111)$ surface. From such a very sharp observation, this result suggests that the etching while circulating the $\mathrm{NH}_{4} \mathrm{~F}$ solution in the cell was done without problems, and the sharp peak results that $\mathrm{Si}$ surface flat and hydrogen-terminated at the atomic level was formed [15] [16] [17].

Di-2-ethylhexyl sulfosuccinate sodium salt (Aerosol OT) as a double-stranded surfactant was used to investigate adsorbed monolayers. In situ ATR-FTIR measurement was carried out by circulating $1 \times 10^{-2} \mathrm{M}$ aerosol OT in this system. The structural formula of the aerosol OT is shown in Figure 4.

Figure 5 shows the IR spectrum after flowing the aerosol OT solution for 240 minutes with no bias. Thereafter, the IR spectrum after holding the potential for 240 minutes by applying a potential to the $\mathrm{Si}(111)$ at $-700 \mathrm{mV}$ (vs. $\mathrm{Ag} / \mathrm{AgCl}$ ), or no bias were shown. At this time, no current almost flowed.

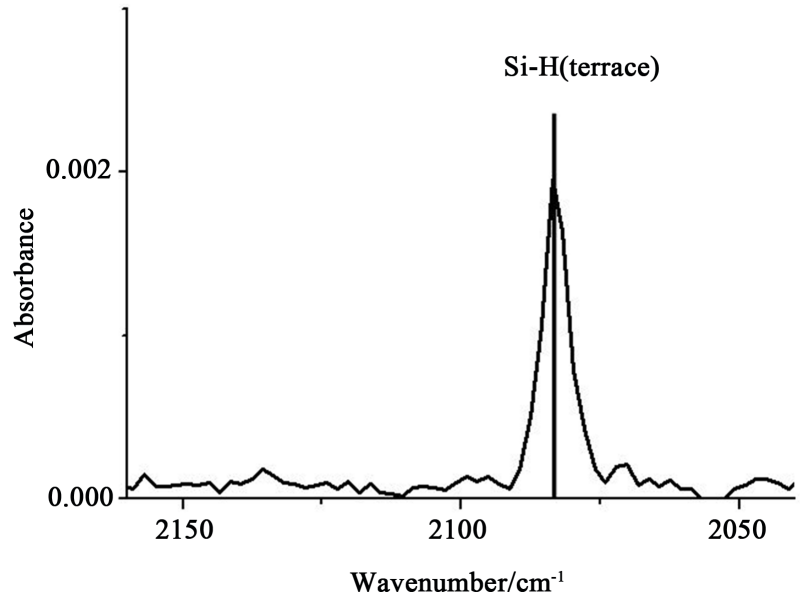

Figure 3. IR spectrum at hydrogen termination on $\mathrm{Si}(111)$ surface with $\mathrm{NH}_{4} \mathrm{~F}$ solution by using the circulation system. 


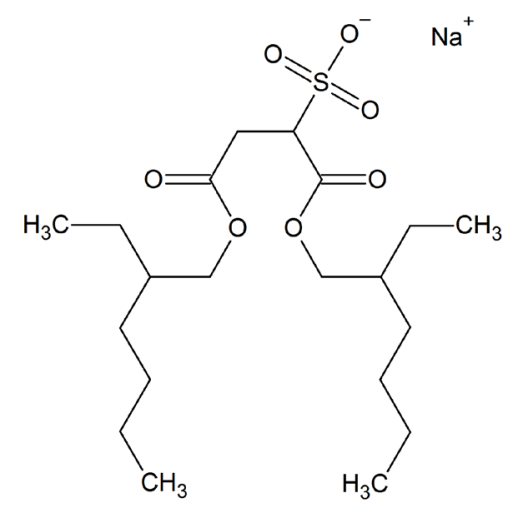

Figure 4. Structure molecular formula of the aerosol OT.

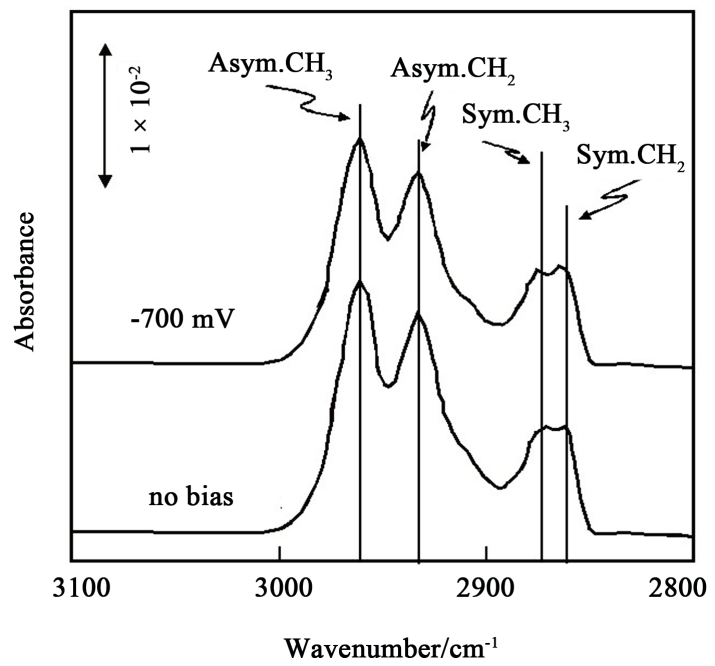

Figure 5. IR spectra of $\mathrm{CH}_{\mathrm{x}}$ at imposing no bias and $-700 \mathrm{mV}$ (vs. $\mathrm{Ag} / \mathrm{AgCl}$ ).

The peak intensity of $\mathrm{CH}_{\mathrm{x}}$ hardly changed even after applying the potential. Also, the peak intensity ratio of methyl group and methylene group did not change. Therefore, these results would indicate that the amount and orientation of the adsorption layer would not change by imposing less-noble bias [18] [19].

Similarly, after flowing the aerosol OT solution for $240 \mathrm{~min}$ with no bias, a noble potential was applied to the $\mathrm{Si}(111)$ at $+700 \mathrm{mV}$ (vs. $\mathrm{Ag} / \mathrm{AgCl}$ ), and the in situ imposing bias ATR-FTIR spectra were shown in Figure 6. At this time, no current almost flowed. The peak intensity of $\mathrm{CH}_{\mathrm{x}}$ by the aerosol OT modified on the $\mathrm{Si}(111)$ surface decreased by imposing $+700 \mathrm{mV}$. These results suggest that this adsorbed aerosol OT gradually desorb by imposing the noble bias. Furthermore, the peak intensity ratio of the methyl group and the methylene group also varies. Hence, the adsorption amount of the surfactant does not only decreases but the orientation might become random by applying the noble potential [20] [21].

Therefore, the spectral changes of Si-H peak by imposing $+700 \mathrm{mV}$ (vs. $\mathrm{Ag} / \mathrm{AgCl}$ ) have been investigated with the state of hydrogen-terminated Si surface shown in Figure 7. After applying the noble potential, the Si-H (terrace) 


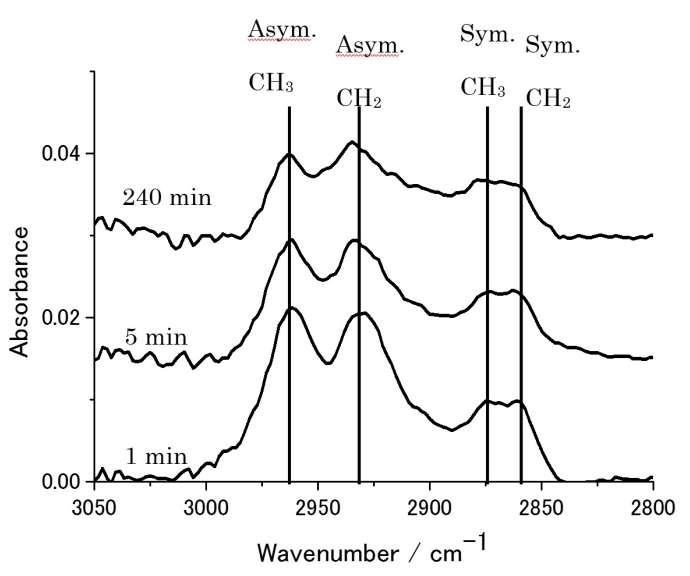

Figure 6. IR spectra of $\mathrm{CH}_{\mathrm{x}}$ at imposing $+700 \mathrm{mV}$ (vs. $\mathrm{Ag} / \mathrm{AgCl}$ ) for $1 \mathrm{~min}, 5 \mathrm{~min}$ and 240 $\min$.

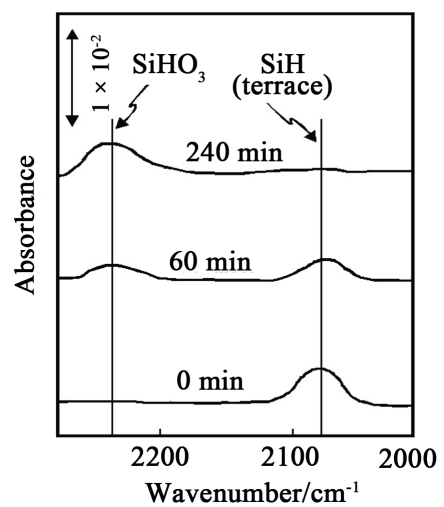

Figure 7. IR spectra of $\mathrm{SiH}$ and $\mathrm{SiHO}_{3}$ at imposing $+700 \mathrm{mV}$ (vs. $\mathrm{Ag} / \mathrm{AgCl}$ ) for $0 \mathrm{~min}$ (no bias), $60 \mathrm{~min}$ and $240 \mathrm{~min}$.

peak intensity decreased. On the other hand, $\mathrm{SiHO}_{3}$ peak intensity increased as silicon oxide. These results suggest that oxidation of Si(111) surface proceeded by applying a noble potential. Oxidation of the hydrogen-terminated Si surface will be back-bond oxidation type in which oxygen atoms bonded at the behind of hydrogen-terminated $\mathrm{Si}$ atoms are conceivable as the $\mathrm{SiHO}_{3}$ as shown in Figure 8. In this system, as the sample solution flows through the hydrogen-terminated Si surface, the peak of $2250 \mathrm{~cm}^{-1}$ based on Si back-bond oxidation type would appear over time, and it gradually increases. Therefore, the oxidation of hydrogen-terminated $\mathrm{Si}(111)$ due to the applying of the noble potential will be caused by three oxygen atoms into Si back-bond.

From the above, when the no potential or the less-noble potential is applied, the surface of hydrogen-terminated $\mathrm{Si}(111)$ is maintained as shown in Figure 9(a). These results will suggest that the surface is modified by the aerosol OT whose orientation is maintained by the alkyl group having hydrophobicity. On the other hand, when the noble potential is applied, this result will suggest that the aerosol OT was desorbed by the back-bond oxidation at the $\mathrm{Si}(111)$ as shown in Figure 9(b). 


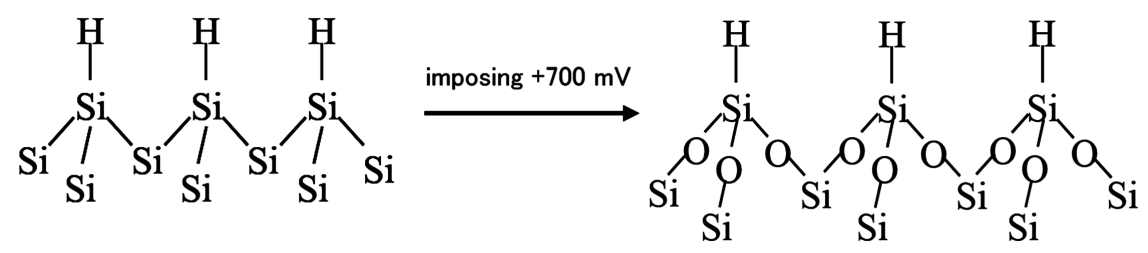

Figure 8. Schematic diagram of Si back-bond type oxidation of hydrogen-terminated Si(111) surface.

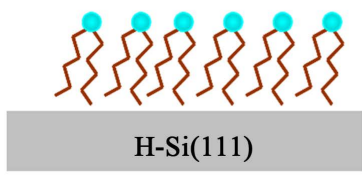

(a)

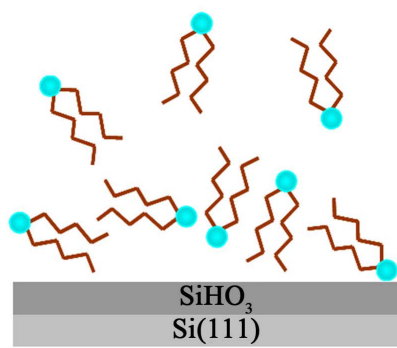

(b)

Figure 9. Orientation and desorption of the aerosol OT on the Si(111) surface by imposing (a); no bias or negative bias, and (b); positive bias.

\section{Conclusion}

Hydrogen-terminated $\mathrm{Si}(111)$ was formed by using the circulation system. After that, when the aerosol OT solution was circulated, it was found from the IR spectrum that a monolayer was formed on the $\mathrm{Si}(111)$ by the adsorption. No change was observed in the IR spectrum when the less-noble potential was applied. On the other hand, when the noble potential was applied, the decrease in adsorption amount was observed. This result will suggest the oxidation by three oxygen atoms in the back-bond of silicon.

\section{Acknowledgements}

This work was supported by JSPS KAKENHI Grant Number 15K05602.

\section{Conflicts of Interest}

The authors declare no conflicts of interest regarding the publication of this paper.

\section{References}

[1] Nakano, M., Osaka, I. and Takimiya, K., (2017) Control of Major Carriers in an Ambipolar Polymer Semiconductor by Self-Assembled Monolayers. Advanced Materials, 29, Article ID: 1602893. https://doi.org/10.1002/adma.201602893

[2] Simoncelli, S., Li, Y., Cortés, E. and Maier, S.A. (2018) Nanoscale Control of Molecular Self-Assembly Induced by Plasmonic Hot-Electron Dynamics. ACS Nano, 12, 2184-2192. https://doi.org/10.1021/acsnano.7b08563

[3] Shi, Y., Jiang, L., Liu, J., Tu, Z., Hu, Y., Wu, Q., Yi, Y., Gann, E., McNeill, C.R., Li, H., Hu, W., Zhu, D. and Sirringhaus, H. (2018) Bottom-Up Growth of n-Type Monolayer Molecular Crystals on Polymeric Substrate for Optoelectronic Device Ap- 
plications. Nature Communications, 9, Article No. 2933.

https://doi.org/10.1038/s41467-018-05390-3

[4] Yuan, Z., Xiao, X., Li, J., Zhao, Z., Yu, D. and Li, Q. (2018) Self-Assembled Graphene-Based Architectures and Their Applications. Advanced Science, 5, Article ID: 1700626. https://doi.org/10.1002/advs.201700626

[5] Dong, D., Yap, L.W., Smilgies, D.-M., Si, K.J., Shi, Q. and Cheng, W. (2018) TwoDimensional Gold Trisoctahedron Nanoparticle Superlattice Sheets: Self-Assembly, Characterization and Immunosensing Applications. Nanoscale, 10, 5065-5071. https://doi.org/10.1039/C7NR09443D

[6] Panda, S.S., Katz, H.E. and Tovar, J.D. (2018) Solid-State Electrical Applications of Protein and Peptide Based Nanomaterials. Chemical Society Reviews, 47, 3640-3658. https://doi.org/10.1039/C7CS00817A

[7] Dumas, P., Chabal, Y.J. and Jakob, P. (1992) Morphology of Hydrogen-Terminated $\mathrm{Si}(111)$ and $\mathrm{Si}(100)$ Surfaces upon Etching in HF and Buffered-HF Solutions. Surface Science, 269-270, 867-878. https://doi.org/10.1016/0039-6028(92)91363-G

[8] Jakob, P. and Chabal, Y.J. (1991) Chemical Etching of Vicinal Si(111): Dependence of the Surface Structure and the Hydrogen Termination on the $\mathrm{pH}$ of the Etching Solutions. The Journal of Chemical Physics, 95, 2897-2909.

https://doi.org/10.1063/1.460892

[9] Jakob, P., Chabal, Y.J., Raghavachari, K., Becker, R.S. and Becker, A.J. (1992) Kinetic Model of the Chemical Etching of Si(111) Surfaces by Buffered HF Solutions. Surface Science, 275, 407-413. https://doi.org/10.1016/0039-6028(92)90813-L

[10] Aoki, H., Hasegawa, K., Tohda, K. and Umezawa, Y. (2003) Voltammetric Detection of Inorganic Phosphate Using Ion-Channel Sensing with Self-Assembled Monolayers of a Hydrogen Bond-Forming Receptor. Biosensors and Bioelectronics, 18, 261-267. https://doi.org/10.1016/S0956-5663(02)00177-X

[11] Xiao, K.P., Bühlmann, P. and Umezawa, Y. (1999) Ion-Channel-Mimetic Sensing of Hydrophilic Anions Based on Monolayers of a Hydrogen Bond-Forming Receptor. Analytical Chemistry, 71, 1183-1187. https://doi.org/10.1021/ac9809635

[12] Camillone, N., Leung, T.Y.B. and Scoles, G. (1997) A Low Energy Helium Atom Diffraction Study of Decanethiol Self-Assembled on Au(111). Surface Science, 373, 333-349. https://doi.org/10.1016/S0039-6028(96)01167-3

[13] Hobara, D. and Kakiuchi, T. (2001) Domain Structure of Binary Self-Assembled Monolayers Composed of 3-Mercapto-1-Propanol and 1-Tetradecanethiol on $\mathrm{Au}(111)$ Prepared by Coadsorption. Electrochemistry Communications, 3, 154-157. https://doi.org/10.1016/S1388-2481(01)00127-8

[14] Chen, S., Li, L., Boozer, C.L. and Jiang, S. (2001) Controlled Chemical and Structural Properties of Mixed Self-Assembled Monolayers by Coadsorption of Symmetric and Asymmetric Disulfides on $\mathrm{Au}(111)$. The Journal of Physical Chemistry B, 105, 2975-2980. https://doi.org/10.1021/jp0040650

[15] Kimura, Y., Kondo, Y. and Niwano, M. (2001) Initial Stages of Porous Si Formation on Si Surfaces Investigated by Infrared Spectroscopy. Applied Surface Science, 175-176, 157-162. https://doi.org/10.1016/S0169-4332(01)00029-0

[16] Niwano, M., Miura, T., Tajima, R. and Miyamono, N. (1996) Infrared Study of Chemistry of Si Surfaces in Etching Solution. Applied Surface Science, 100-101, 607-611. https://doi.org/10.1016/0169-4332(96)00348-0

[17] Niwano, M., Kondo, Y. and Kimira, Y. (2000) In Situ Infrared Observation of Etching and Oxidation Processes on Si Surfaces in $\mathrm{NH}_{4} \mathrm{~F}$ Solution. Journal of the Electrochemical Society, 147, 1555-1559. https://doi.org/10.1149/1.1393393 
[18] Singh, P.K., Adler, J.J., Rabinovich, Y.I. and Moudgil, B.M. (2001) Investigation of Self-Assembled Surfactant Structures at the Solid-Liquid Interface Using FT-IR/ATR. Langmuir, 17, 468-473. https://doi.org/10.1021/la000981t

[19] Jang, W.-H. and Miller, J.D. (1995) Molecular Orientation of Langmuir-Blodgett and Self-Assembled Monolayers of Stearate Species at a Fluorite Surface As Described by Linear Dichroism Theory. The Journal of Physical Chemistry, 99, 10272-10279. https://doi.org/10.1021/j100025a031

[20] Sato, Y., Ye, S., Haba, T. and Uosaki, K. (1996) Potential Dependent Orientation and Oxidative Decomposition of Mercaptoalkanenitrile Monolayers on Gold. An in Situ Fourier Transform Infrared Spectroscopy Study. Langmuir, 12, 2726-2736. https://doi.org/10.1021/la950675t

[21] Zhang, H.-L., Chen, M. and Li, H.-L. (2000) Study on Two-Component Matrix Formed by Coadsorption of Aromatic and Long Chain Mercaptans on Gold. The Journal of Physical Chemistry B, 104, 28-36. https://doi.org/10.1021/jp991391a 